\title{
Parcelas permanentes en fincas cafetaleras: una oportunidad para observar la dinámica productiva de la región cafetalera de Coatepec
}

\author{
M. J. Gómez¹,2 - G. C. Ortíz'1,3 - C. R. Cerdán”1,3
}

\begin{abstract}
RESUMEN
El contar con observaciones de la realidad del heterogéneo manejo cafetalero se hace necesario para orientar la investigación del sector. Esta nota presenta cómo y por qué se establecieron 15 parcelas permanentes en cafetales de la región, por parte del Observatorio de la Cafeticultura Veracruzana. Desde 2015 se están tomando datos referentes a cafetos, árboles, suelos y manejo, permitiendo la realización de tesis de licenciatura y posgrado. Se propone mantener, sistematizar y divulgar las observaciones realizadas.
\end{abstract}

\begin{abstract}
In order to focus coffee research, it is a priority to have observations regarding the heterogeneous management that coffee farmers do. This note reports how and why the Coffee Observatory of Veracruz has stablished 15 coffee permanent plots. Since 2015 data regarding coffee plants, trees, soils and coffee management have been compiled to support undergraduate and graduate thesis. It is proposed to keep, systematize and publish these observations.
\end{abstract}

Palabras Clave: investigación agrícola, generación de información, sistemas agroforestales, docencia universitaria, manejo de fincas.

Keywords: agricultural research, knowledge information, agroforestry systems, university teaching, farm management

U na de las acepciones que la palabra "investigar" tiene es la de "realizar actividades intelectuales y experimentales de modo sistemático con el propósito de aumentar los conocimientos sobre una determinada materia". Estos conocimientos, para ser considerados científicos, deben cumplir con varias características, principalmente que sean confiables y comprobables. Observar, por su parte, significa mirar algo con mucho detenimiento para adquirir algún conocimiento sobre su comportamiento o sus característi- cas. Sin embargo, observar e investigar no son sinónimos, sino más bien, la observación es parte fundamental de la investigación. Buenas observaciones son fundamentales para formular problemas de investigación, así como para identificar los factores importantes que describen el problema.

En las ciencias agropecuarias es común la carencia de observaciones suficientes en las situaciones reales de producción, tanto en tiempo (se observa por poco tiempo), como en cobertura (no se observa en todas las regiones).

1 Facultad de Ciencias Agrícolas - Xalapa, Universidad Veracruzana

2 Laboratorio de Ecoagricultura, Facultad de Ingeniería Agronómica, Universidad del Tolima, Colombia.

3 Observatorio de la Cafeticultura Veracruzana, Universidad Veracruzana.

Autor para correspondencia: ccerdan@uv.mx 
Es decir, por ejemplo en la producción de café en Veracruz, no se han hecho las observaciones suficientes para saber cómo ha cambiado el manejo que los cafetaleros han venido haciendo desde que se estableció el cultivo en la zona; además las observaciones que se tienen son de determinados lugares, que dada la heterogeneidad del manejo, no representan las formas en las cuales los productores manejan sus fincas.

Un buen ejemplo de esto sería el uso de variedades de café. De manera rápida se podría decir que los productores antes usaban variedades "tradicionales", de porte alto, que requerían de más sombra; y que en los últimos años han empezado a usar variedades "modernas", de porte bajo, resistentes a enfermedades, que requieren de menos sombra de árboles. Sin embargo, aunque esta percepción es real, desconocemos su magnitud. No podemos decir en qué proporción se está dando este cambio, en qué años, por qué razones, hacia qué variedades. Obviamente tampoco podemos decir cómo repercute el cambio de variedades para la zona en los niveles de producción, o en la calidad del café, o en el manejo de enfermedades, como la roya anaranjada. Al igual que con el uso de variedades, tampoco sabemos cómo ha evolucionado el manejo de suelos, o los árboles presentes en los cafetales, los productos químicos usados, ni los rendimientos y mucho menos la dinámica hídrica y climática en los sistemas agroforestales cafetaleros.

En la investigación forestal (el café se considera agroforestal por crecer bajo árboles de sombra) muchos de los conocimientos cientí- ficos que se han tenido son resultado de parcelas que han sido evaluadas reiteradamente. A estos sitios se las llama "parcelas permanentes". Estas parcelas permanentes son la base para que cada país haga el inventario de sus recursos forestales nacionales. Por ejemplo, en México, la Comisión Nacional Forestal (CONAFOR) cuenta con 3369 parcelas distribuidas nacionalmente donde sistemáticamente evalúa el estado forestal. Con estas consideraciones, el Observatorio de la Cafeticultura Veracruzana viene trabajando con una red de parcelas en cafetales de la región donde se pretende compilar sistemáticamente diversos datos referentes a la producción de café. Estas parcelas se manejan únicamente bajo las decisiones de los productores, sin recomendaciones técnicas de parte de investigadores, ya que el objetivo es observar las diferentes formas en las que los productores trabajan sus fincas (Figura 1). Esta red de parcelas articula las acciones desarrolladas por Observa-café. El objetivo es lograr que estas parcelas sean permanentes, para poder tener a futuros datos comparables en tiempo. Esta nota describe brevemente cómo han sido establecidas estás parcelas permanentes.

La región cafetalera de Coatepec incluye 7 municipios y cuenta con cerca de 12000 productores que cultivan principalmente Coffea arabica. El ecosistema original es el Bosque Mesófilo de Montaña, la franja orográfica donde se produce café varía en altitud de los 900 a los 1300 metros sobre el nivel del mar, con temperaturas promedio anuales de 23 y $16^{\circ} \mathrm{C}$, respectivamente, y precipitaciones anuales de 1330 a 2100. En esta región se establecieron 15

Figura 1. Sistema agroforestal cafetalero intensivo con sombra dominante de Inga en el municipio de Emiliano Zapata, Ver. (Foto: Mario J. Gómez-Martínez).

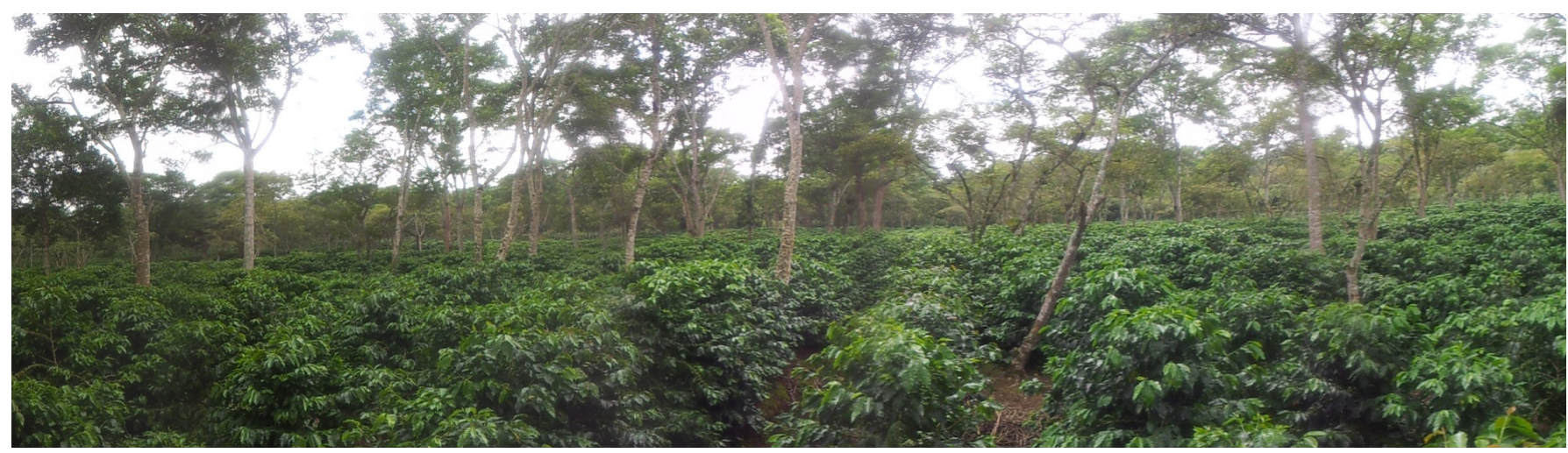


parcelas (cada una de 1000 m2) en el año 2015, distribuidas en los municipios de Coatepec, Emiliano Zapata, Xico y Teocelo (Figura 2). Estas parcelas cumplen con las siguientes características que las hacen representativas de la heterogeneidad de la zona: ubicación (cubren 4 municipios y se encuentran a menos de $3 \mathrm{~km}$ de alguna estación meteorológica), manejo (van desde parcelas intensivas hasta tradicionales), cafetos (de 2300 a 8600 cafetos ha-1), altitud (la más baja a 905 msnm, la más alta a 1302), suelos (de migajón limoso a arcillosos), cobertura arbórea (desde 40 hasta 180 árboles por hectárea).

Hasta el momento en cada una de las 15 parcelas se han tomado datos sobre los cafetos (variedad, altura, diámetro a $10 \mathrm{~cm}$ desde suelo, diámetro a la mitad del tallo, altura y longitud del primer para de ramas y enfermedades), suelos (parámetros fisicoquímicos), componente leñoso (especie, altura, diámetro a la altura del pecho y área de la copa), prácticas de manejo (aplicación de agroquímicos y podas) y estimación de la cosecha. Así mismo, se realizan 4 tesis de licenciatura estudiando diversos temas (resistencia de los suelos a la penetración, densidad óptima de cafetos, bioma microbiano -bacterias- y mesofauna). Aunado a 1 tesis de doctorado que se encuentra en ejecución, donde se estudia la relación entre árboles, suelos y clima con la producción de café. La información obtenida se analiza estadísticamente con pruebas paramétricas y no paramétricas, como ANAVA, correlaciones, análisis clúster, entre otros. En algunos casos se emplea estadística descriptiva para analizar la información.

El reto actual es continuar periódicamente con la colecta de datos para poder a futuro hacer estudios comparativos, evaluar la pertinencia de programas de gobierno, determinar trayectorias de la cafeticultura, complementar con trabajos socioeconómicos. Para esto, como ocurre con muchas parcelas permanentes, la problemática será el contar con financiamiento para continuar con la toma de datos a las fincas cafetaleras estudiadas.

Información suplementaria: Detalles sobre la localización, observaciones realizadas y trabajos de tesis terminados y en proceso realizados en estas 15 parcelas se encuentran la página del Observatorio de la Cafeticultura Veracruzana www.uv.mx/observacafe/

Figura 2. Distribución de las 15 parcelas dentro de la Región Cafetalera de Coatepec.

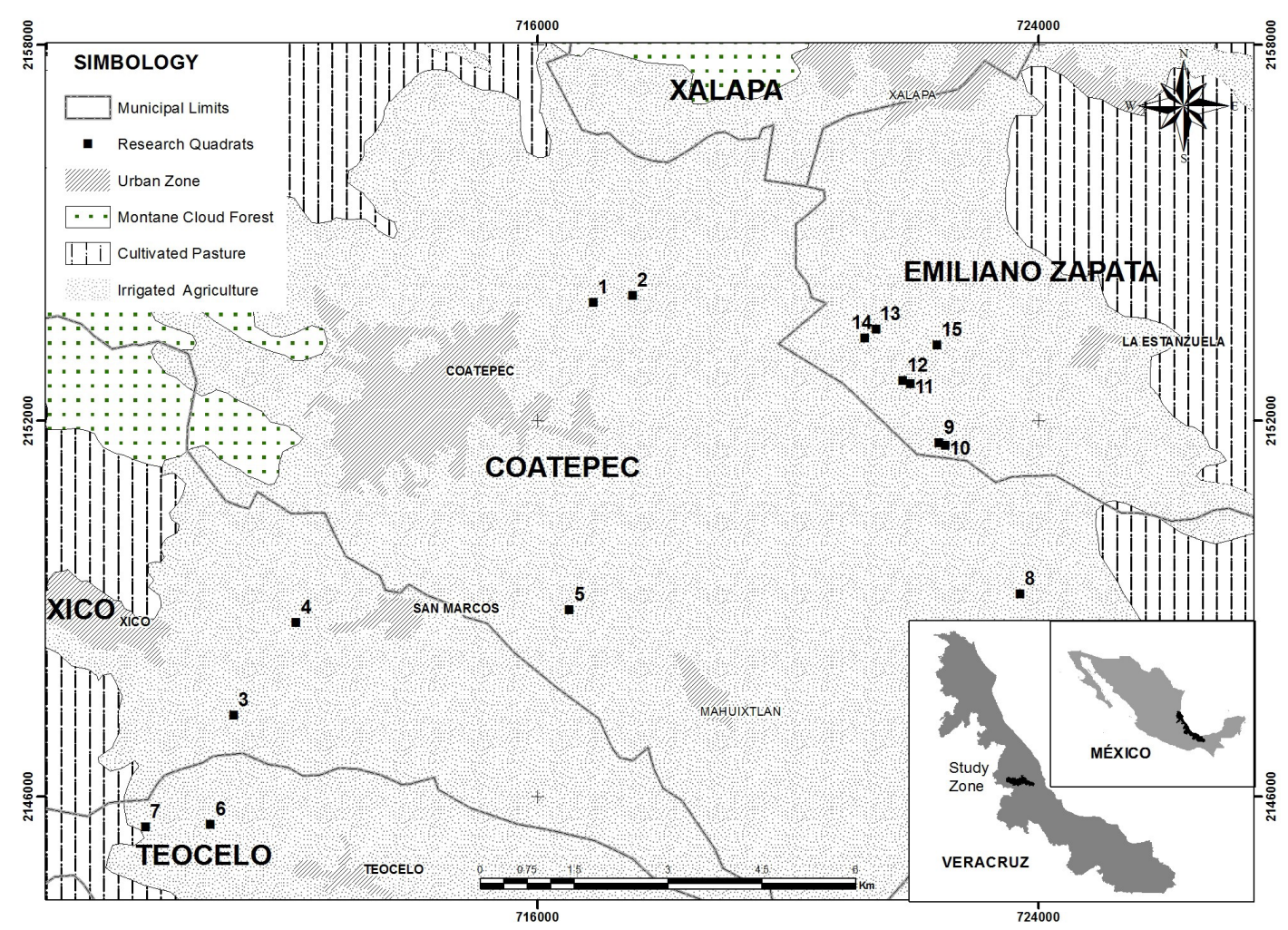

